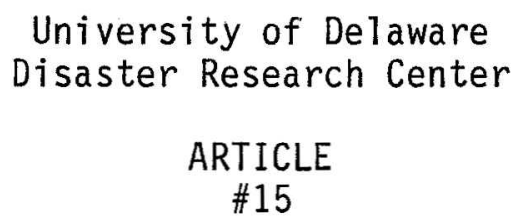

Russell R. Dynes and

E.L. Quarantelli

Reprinted from Trans-Action 5 (May 1968): 9-14. 



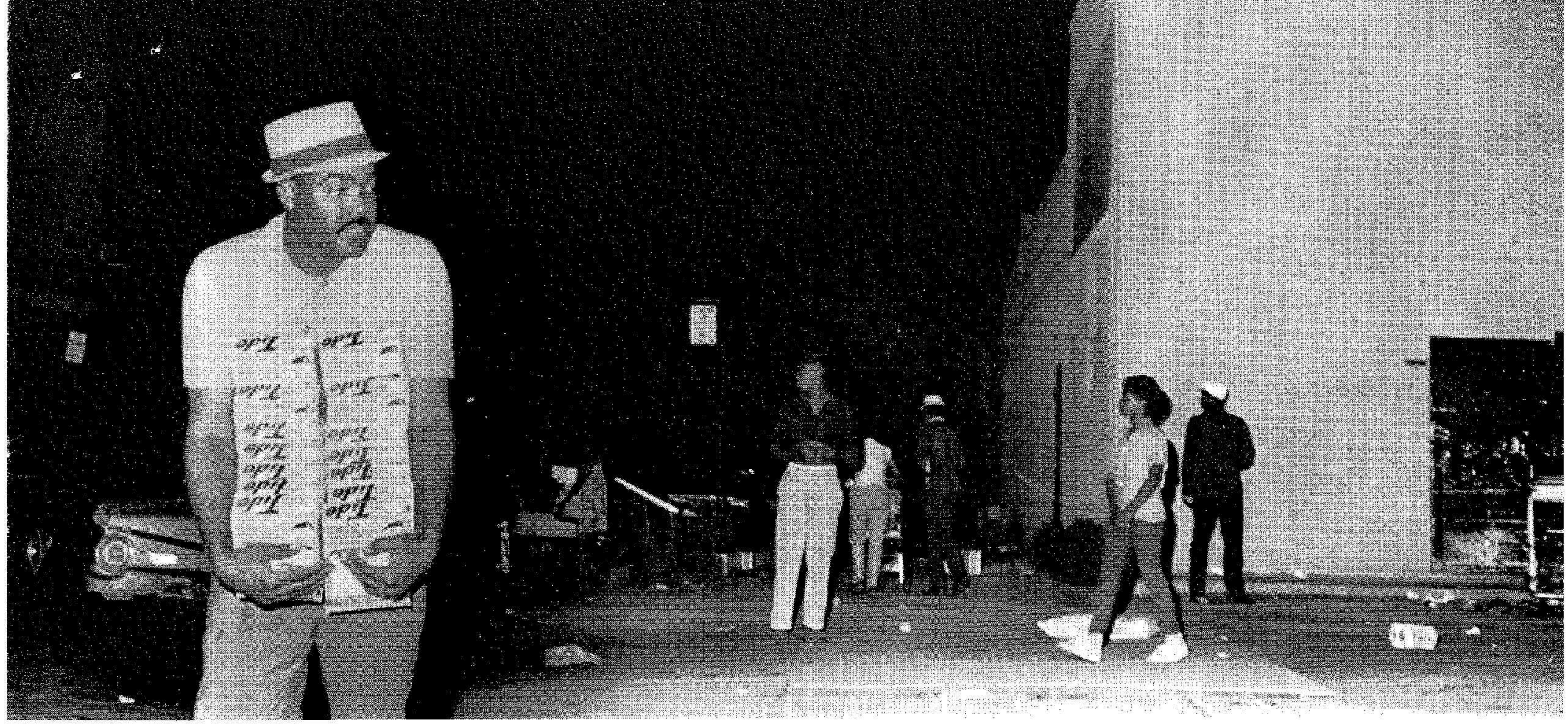

\section{Wbat Looting in Civil Disturbances Really Means}

Unlike the looting after disasters, looting in civil disturbances

conveys an important message from the deprived sectors of the population

\section{RUSSELL DYNES \& E.L. QUARANTELLI}

In March and April of this year, there were civil disturbances in Memphis, Tenn, Washington, D.C., Chicago, Pittsburgh, and Baltimore. Many films and photographs were taken of people looting other people's property. These looting incidents conformed to the pattern, for according to many reports people may be found looting when a community is having certain kinds of crises. One of these crises is caused by a natural disaster-a flood, hurricane, and so forth And the other is caused by a civil disturbance, like the ones that have hit American cities every summer since the Watts outbreak of August 1965.

Natural disasters and civil disturbances give people a chance to help themselves to other people's goods. Yet there are important, fascinating differences between what happens in these two crisis situations. For example, looting is far more common in civil disturbances than in disasters. Then too, the kinds of goods taken during these two crises are different. And public disdain for the act varies. Sometimes taking other people's property during a community crisis is not even considered looting!

In order to examine the differences between the two crisis situations, let us analyze what happens to private property during natural disasters, and then contrast this with the transfers of property that take place during civil disorders.

The word "looting" has military roots. It implies that invading armies take property by force, generally when the rightful owner cannot protect it. Similarly, in civil disturbances "invading armies" plunder property left unguarded when the owner is forced out by violence or the threat of violence. During disasters, according to common belief, "invading armies" of opportunists take property left unguarded when the owner is forced out by the disaster.

The looting that takes place in these situations is usually interpreted as evidence of human depravity In periods of natural or civil chaos, goes the explanation, the human animal is stripped of his usual social controls. Without them, he is not a noble savage, but an ignoble one. For the general public, reports of looting are easy to incorporate into their images of the "criminal elements" who clean out the corner grocery during a racial disturbance, or the fiends and ghouls who roam disaster-stricken areas.

After the Galveston hurricane of 1900, published accounts told of people being summarily shot when 
they were caught with pocketsful of severed fingers with rings on them. In 1906, after the San Francisco earthquake and fire, the Los Angeles Times reported that "looting by fiends incarnate made a hell broth of the center of the ruined district. Sixteen looters were shot out of hand on April 19, while robbing the dead." In his reconstruction of events after the earthquake, reporter Q.A. Bronson noted "reports ... of ... looters wantonly shot in their tracks by Federal troops, miscreants hanged in public squares, and ghouls found cutting off the fingers and ears of corpses for rings and earrings attached."

Today, most radio and television accounts of disasters are less dramatic, but looting is still a major theme. After a tornado hit some suburbs of Chicago in April 1967, a county sheriff reportedly announced that "orders had gone out that beginning at 10 P.M. Friday, any looters . . were to be shot on sight." After a power failure blacked out the Cincinnati area in May 1967, a wire-service story told of the smashing of store windows and looting in Cincinnati and in neighboring Newport and Covington, $\mathrm{Ky}$.

Public officials, expecting certain kinds of community emergencies to activate human depravity, often request additional law enforcement. They mobilize National Guard units and take extra security measures. These steps are often taken upon the first reports of a civil disturbance or a natural disaster. Frequently, before the situation has even developed, television and radio will report what is expected to bappen - the fear of looting and the steps being taken to prevent it.

That most people are concerned about looting in civil disorders and disasters is beyond dispute. Reliable evidence, however, points to a surprising fact: While looting dearly does occur in civil disturbances, in disaster situations it is very rare.

Many studies of disasters mention reports of looting, but very few cite authenticated cases. One study that did inquire into actual cases of looting was the National Opinion Research Center (N.O.R.C.) study of White County, Ark, after it was ravaged by a tornado in 1952. In the community that suffered the greatest damage, about 1000 of the 1200 residents were left homeless. A random sample of people from this town and adjacent areas were asked whether they had lost any property by looting. Only 9 percent reported that they, or members of their immediate household, had lost property that they even felt had been taken by looters. And fully one-third of these people were uncertain whether the loss was really due to looters, or whether the missing items had been blown away or buried in the debris. Finally, most of the articles were of little value.

In contrast, 58 percent of the people questioned said they had heard of others' property being stolen. In fact, 9 percent claimed that they had even seen looting in progress or had seen looters being arrested. The N.O.R.C study team on the scene, however, could verify the theft of only two major items-a cash register and a piano.

Other disaster research confirms the rarity of looting A study made after the 1953 floods in the Netherlands found that, although there were many reports of looting, law-enforcement agencies could discover not a single verified case. The Dutch researchers attributed many of the reports of looting to memory lapses in the immediate post-flood period, and pointed out that a number of people who reported thefts later found the missing items. Charles Fritz and J.H. Mathewson, in a review of disaster studies published up to 1956 , concluded that "the number of verified cases of actual looting in peacetime disasters, in the United States and in foreign countries, is small."

More recent studies point in the same direction. The Disaster Research Center at Ohio State University, in field studies of more than 40 disasters both in the United States and abroad, has found extremely few verified cases of looting. Actual police records support these findings. For example, in September 1965, the month Hurricane Betsy struck New Orleans, major crimes in the city fell 26.6 percent below the rate for the same month in the previous year. Burglaties reported to the police fell from 617 to 425 . Thefts of over $\$ 50$ dropped from 303 to 264, and those under $\$ 50$ fell from 516 to 366 .

\section{Misinterpreted Motives}

Since all evidence is that looting is rare or nonexistent in natural disasters, why do reports of looting in disaster situations occur over and over again? And why are these reports persistently believed, even when there is no clear evidence to back them up?

To answer these questions, we need to look at four conditions that usually prevail in the immediate postimpact period: misinterpretations of observed behavior; misunderstandings over property ownership; inflated reports of looting; and sensational coverage of disaster situations by the news media.

Reports of looting are often based on misinterpretation of people's motives. After a disaster, masses of people-often numbering in the thousands-converge on the impact area. Local officials, particularly those with little experience in large-scale emergencies, frequently regard these convergers as sightseers-and, by extension, as potential looters. However, Fritz and Mathewson have shown that there are at least five different types of convergers: the returnees-the disaster survivors who want to go back to the impact area; the anxious - those concerned with the safety of kin and friends; the helpers-those who want to donate 
their services; the curious - those attempting to make some sense out of the unusual events that have occurred; and the exploiters - those seeking private gain from public misfortune. The number in this last category is small and includes, in addition to potential looters, souvenir hunters, relief stealers, and profiteers

The important point is that those who converge on a disaster area have a variety of motives. Community officials often do not seem to recognize this. For example, a property owner whose house has been destroyed may return to the area to sift through the debris of his own home in the hope of recovering lost articles. To a casual observer, his behavior may look like looting. Out-of-town relatives may come into a disaster area with a truck to help their kin collect and store their remaining possessions. People engaged in informal search-and-rescue activities of this sort may also appear to be looters. The souvenir hunter is looking for something that has symbolic rather than material value. But in the disaster context, his behavior too becomes suspect.

Another source of false looting reports is the fact that, although little or no property is stolen in disaster situations, goods are frequently given away. Sometimes there is confusion about which items are free, and who is entitled to them.

In one disaster, the report began circulating that a grocery store had been looted. Investigation revealed that the owner had placed damaged goods outside on the sidewalk, announcing that anyone was welcome to take them. Since his store front had been demolished, however, the line between the free goods and the owner's undamaged stock was vague-and some people who came to get the free goods inadvertently took items from the undamaged stock instead. This misunderstanding was soon cleared up. But an early report of the incident, given to the military authorities in the area, quickly spread throughout the community as an authentic case of looting. And what's more, the looting report was later accepted as valid even by members of the military who had established that it was false.

Overblown estimates of disaster losses are the third source of unfounded looting reports. Officials in a disaster area frequently tend to overestimate the seriousness of the situation. Messages about either the quantity of aid needed or the extent of the damage tend to mushroom as they pass from one person to another. If one official asks another for 100 cots, the second official may relay a request to a third official for 150 cots, and so on. In much the same way, reports of looting get blown out of proportion.

The following incident occurted at a communications center in a major metropolitan area that had been hit by a hurricane: A patrolman in the field, talking over his radio, made a casual comment that, since some store fronts were open and could easily be entered, perhaps a policeman might be dispatched to that location. The patrolman who received this call was busy for a few minutes with other queries. Then he made a call to the state police requesting that a force be rushed to that location-since, he said, "a hell of a lot of looting is going on there."

Sensational news accounts round out the picture. Naturally, the mass media emphasize the dramatic. The atypical and the unique are what catch the newsman's attention. Photographs of disaster areas depict the buildings that are destroyed, not the ones that are still intact. And in press accounts, any stories about looting-including the stories that are inaccurate and inflated-are quickly seized upon and highlighted.

These accounts are often accepted as reasonable descriptions of what is occurring even by community officials themselves. In the absence of up-to-date and direct information, what happened or what is happening is not easy to determine. The phone system may be disrupted, preventing direct feedback of information from field points. Movement may be severely restricted. Direct observation is often impossible. And the pressure for immediate action may prevent anyone from keeping accurate records. Since few people in any community have much first-hand experience with largescale disasters, journalistic accounts become a major means of defining reality. As one police chief said in reply to a question about his knowledge of looting, "Well, I'm not sure. All I know right now is the reports I've heard over the radio."

The upshot of all this is that many reported cases of post-disaster "looting," based on misinterpretation or misunderstanding and publicized by exaggerated or sensational accounts, are not really cases of looting at all. They involve no unlawful appropriations of property.

Still, the fact remains that certain "illegal" appropriations of property do occur in disaster situations. For example, people sometimes break into stores and warehouses without the owner's consent and take medical supplies, cots, generators, and flashlights. Now, is this looting? And if not, why not?

Here we come to the critical element of "property redefinition." Incidents of this sort are not looting. The notion of "property" involves a shared understanding about who can do what with the valued resources within a community. When a disaster strikes, property rights are temporarily redefined: There is general agreement among community members that the resources of individuals become community property. Individual property rights are suspended, so appropriation of private resources-which would normally be considered looting--is temporarily condoned. Before these resources can be given back to private 
use, the needs of the disoriented larger community have to be met.

When a natural crisis occurs, the usual plurality of individual goals gives way to the single, overriding goal of the community - the goal of saving as many lives as possible. Any way of achieving this becomes legitimate. People who are trapped have to be rescued; people who are in dangerous areas have to be evacuated; people who have been injured have to be given medical attention; people who are missing, and pethaps injured, must be found. If this means community appropriation of private search equipment, medical material, and even vehicles, it is implicitly viewed as necessary. In one case, a city attorney even made it official: He announced that people were to disregard any laws that would interfere with the search-andrescue efforts going forward in the central part of the city. This meant formally sanctioning breaking into and entering private stores and offices in the city.

The redefinition of property that occurs during natural disasters, then, almost defines looting out of existence. Almost, but not quite. For implicit in the redefinition is the idea that access to the redefined property is limited to community members, and for community ends. If outsiders enter the disaster area and begin appropriating private property for their own use, it is still looting. And in fact, evidence indicates that the few verified instances of looting that do occur in natural disasters are almost always of this sortthat is, they are committed by outsiders.

Occasionally there are authenticated reports that seem to contradict our finding that looting in natural disasters is very rare. One example is the looting that occurred during the very heavy snowstorms that paralyzed Chicago in late January and early February 1967. $A$ few of the incidents reported were probably routine burglaries, but others were clearly looting. They were not randomly distributed by location, and most of the cases occurred in the same neighborhoods-and sometimes on exactly the same streets - where looting had taken place in the civil disturbances during the summer months of 1966. Along Chicago's Roosevelt Road, for example, looting took place on some of the very same blocks.

This suggests that the looting that occurred in Chicago during the snowstorm was actually a continuation, or perhaps a resurgence, of the earlier civil disturbance. For the general public, the habit of viewing civil disturbances as exclusively summer events probably obscured the true nature of the snowstorm looting. But some local policemen clearly interpreted the looting as a winter recurrence of the summer's civil disorders.

In contrast to what happens in a disaster situation, looting in civil disturbances is widespread, and the loot-

The victim of a flood in the Southwest

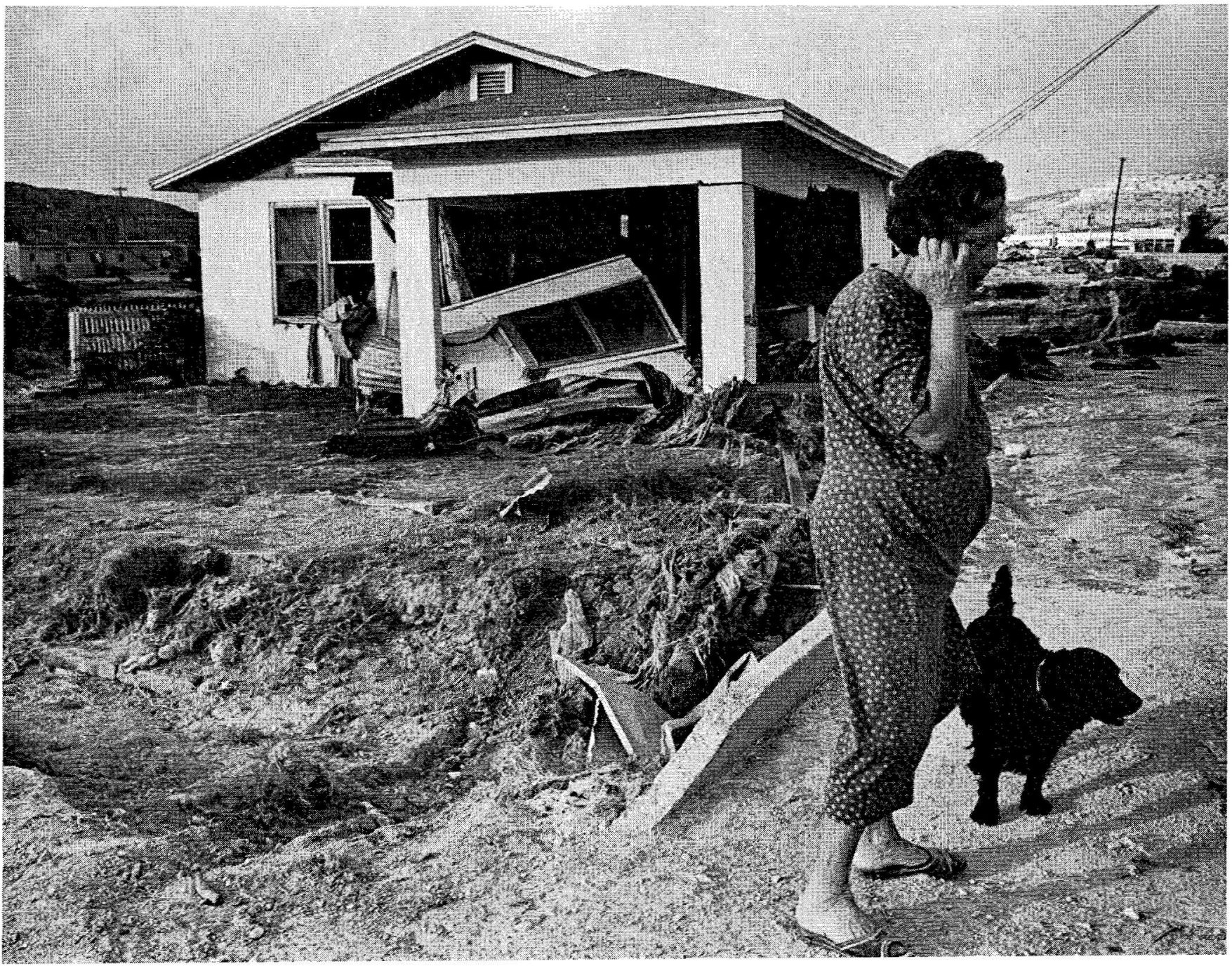


ers are usually members of the immediate community. During the past few summets, films and photographs have shown looting actually in progress. The McCone Commission reported that about 600 stores were looted or burned in Watts. In Newark, around 1300 people were arrested, mostly for taking goods. In the July 1967 holocaust in Detroit, unofficial estimates were that about 2700 stores were ransacked.

\section{Redefinition of Property}

Disasters and civil disturbances are alike in that the normal order and organization of the community is disrupted. In addition, there is, in both situations, a temporary redefinition of property rights. But the two situations differ in other respects. In a disaster, there is general agreement among community members about community goals, especially about saving lives. As a result, by general agreement, all the resources are put at the disposal of the total community until emergency needs are met. A civil disturbance, on the other hand, represents conflict-not consensus-on community goals. The outbreak itself represents disagreement over property rights within the community. Access to existing resources is questionable, and often there is open challenge to prior ownership.

The critical role of attitudes toward property in determining the nature of looting is best seen by contrasting the looting that occurs in civil disturbances with that found in disasters. There are three significant differences. As already noted, widespread looting does occur in civil disturbances, while it is infrequent in disasters. Further, the looting in civil disturbances is selective, focusing on particular types of goods or possessions, often symbolic of other values. And, while out-and-out looting is strongly condemned in disaster situations, looters in civil disturbances receive, from certain segments of the local community, strong social support for their actions.

The occurrence of looting in civil disturbances needs no further documentation. And selectivity can be seen in the fact that, in racial outbreaks, looters have concentrated overwhelmingly on certain kinds of stores. In Watts, Newark, and Detroit, the main businesses affected were groceries, supermarkets, and furniture and liquor stores. In contrast, banks, utility stations, industrial plants, and private residences have been generally ignored. Apartments and homes have been damaged, but only because they were in or near burned business establishments. Public installations such as schools and Office of Economic Opportunity centers have also been spared. There has not been indiscriminate looting. Certain kinds of consumer goods have been almost the only targets.

Looters in civil disturbances are also likely to receive ${ }^{x}$ support from many people in their community. Spiral- ing support coincides with shifts in property redefinitions, and these shifts occur in three stages. Initial looting is often a symbolic act of defiance. The second phase, in which more conscious and deliberate plundering develops, is possibly spurred on by the presence of delinquent gangs that loot more from need or for profit than for ideological reasons. Finally, in the third stage, there is widespread seizure of goods. At this point, looting becomes the socially expected thing to do. For example, a sociological survey at U.C.L.A. found that nearly one-fourth of the population participated in the Watts outbreak (although all of these participants probably did not engage in the looting).

If looting means strictly the taking of goods, little of it occurs in the first phase of civil disturbances. Instead, destructive attacks are most frequently directed against symbols of authority in the community. Police cars and fire trucks are pillaged and burned. What is involved here is perhaps illustrated most clearly in other kinds of civil disturbances, such as some of those created by college students. One of the authors once watched a crowd of students determinedly attack, for over an hour, an overhead traffic light. It conveniently symbolized the city administration and police - the actual target of the demonstrators' wrath. In racial civil disturbances, the police and their equipment are also seen as obvious symbols of the larger community toward which the outbreak is directed. How intense this focus can be was shown in the Watts disturbance. About 168 police cars and 100 pieces of fire-fighting equipment were damaged or destroyed.

The full redefinition of certain property rights occurs next. The "carnival spirit" observed in the Newark and Detroit disturbances did not represent anarchy. It represented widespread social support for the new definition of property. In this phase, there is little competition for goods. In fact, in contrast to the stealthy looting that occasionally occurs in disaster situations, looting in civil disturbances is quite open and frequently collective. The looters often work together in pairs, as family units, or in small groups. Bystanders are frequently told about potential loot. And in some instances, as in the Watts outbreak, looters coming out of stores hand strangers goods as "gifts."

Looting in civil disturbances is by insiders - by local community members. These looters apparently come not only from the low socioeconomic levels and from delinquent gangs, but from all segments of the population. During disturbances in Toledo, 91 percent of the 126 adults arrested for taking goods had jobs. A random sample in Detroit found that participants in the outbreak came more or less equally from all income brackets.

In both disasters and civil disturbances, there is a redefinition of property rights within the community. 
The community authorities, however, respond very differently to the two situations. In disasters, responsible officials tolerate, accept, and encourage the transition from private to community property. In civil disturbances, community authorities see looting as essentially criminal behavior-as a legal problem to be handled forcefully by the police. And many segments of the larger community, especially middle-class people, with their almost sacred conception of private property, tend to hold the same view. This view of looting in civil disturbances fits in neatly with the ideas they already have about the criminal propensities of certain ethnic groups, notably Negroes.

\section{Looting as a Mass Protest}

At one level, there is no question that looting in civil disturbances is criminal behavior. But the laws that make it so are themselves based on dominant conceptions of property rights. Widespread looting, then, may perhaps be interpreted as a kind of mass protest against our dominant conceptions of property.

Mass protest is not new in history. According to George Rudé's analysis, in his book The Crowd in History, demonstrating mobs from 1730 to 1848 in England and France were typically composed of local, respectable, employed people rather than the pauperized, the unemployed, or the "rabble" of the slums. The privileged classes naturally regarded these popular agitations as criminal - as fundamentally and unconditionally illegitimate. Rudé notes, however, that such protest effectively communicated the desires of a segment of the urban population to the élite. E.J. Hobsbawm, in his analysis of the preindustrial "city mob," takes the same position: "The classical mob did not merely riot as a protest, but because it expected to achieve something by its riot. It assumed that the authorities would be sensitive to its movements, and probably also that they would make some immediate concession. ... This mechanism was perfectly understood by both sides."

In current civil disturbances, a similar mechanism and a similar message may be evolving "An attack against property rights is not necessarily "irrational," "criminal," or "pointless" if it leads to a clearer system of demands and responses, in which the needs and obligations of the contending parties are reasonably clear to themselves and to one another. The scope and intensity of current attacks indicate the presence of large numbers of outsiders living within most American cities. If property is seen as a shared understanding about the allocation of resources, and if a greater consensus can be reached on the proper allocation of these resources, many of these outsiders will become insiders, with an established stake in the communities in which they live.
* This, then, is the most fundamental way in which looting in civil disturbances differs from looting after natural disasters: The looting that has occurred in recent racial outbreaks is a bid for the redistribution of property. It is a message that certain deprived sectors of the population want what they consider their fair share-and that they will resort to violence to get it. The fact that looting in riots is more widespread than in disasters, that it concentrates on the prestige items that symbolize the good life, and that it receives the support and approval of many within the deprived sectors who do not participate themselves, merely indicates the true nature and intention of looting under conditions of mass protest.

The basic question now is whether American community leaders can or will recognize that such looting is more than "pointless" or "criminal" behavior. If they do, it may mark the beginning of a new political dialogue, in which the outsiders in our urban communities can express their desires nonviolently to the insidersinsiders who will have finally learned to listen. If not, then in the summers to come, and perhaps in the winters as well, many men and women from the growing urban population may continue to demand a redefinition of property rights through disorder and violence.

\section{FURTHER READING SUGGESTED BY THE AUTHORS:}

Social Organization Under Stress: A Sociological Review of Disaster Studies by Allen Barton (Washington: National Academy of Sciences, 1963). An excellent summary of research on disaster behavior. An updated paperback edition is to be published soon. Convergence Behavior in Disasters by Charles Fritz and J.H Mathewson (Washington, D C : National Academy of Sciences, 1957) . An excellent analysis of actual social control problems in disasters

The Impossible Revolution? Black Power and the American Dream by Lewis Killian (New York: Random House, 1968) A projection into the future of current trends in civil disorders. Riots, Violence and Disorder: Civil Turbulence in Urban Communities edited by Louis Masotti (Beverly Hills, Calif.: Sage Publications, 1968) A series of wide-ranging articles on urban disturbances.

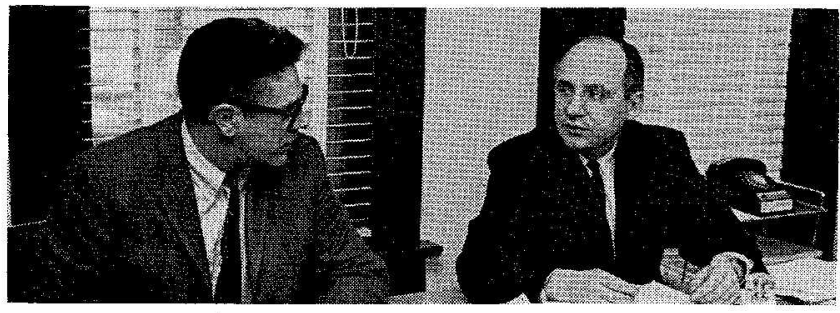

Russell Dynes (left), professor of sociology at Ohio State University, has just published a monograph on Organized Bebavior in Disasters. As co-director of the Disaster Research Center he is doing research on community functioning in acute and diffuse types of crises.

E.I Quarantelli is also a professor of sociology at Ohio State University and co-director of the Disaster Research Center. His current research focuses on the emergence of new groups in emergency situations, and the violation of legal norms during disasters. 